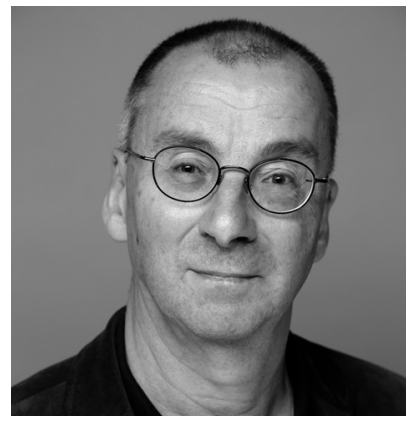

\title{
Zwischen Freiheit und Gerechtigkeit
}

80 bis 90 Prozent seiner Arbeitszeit dient der internen Koordinierung, stellt der deutsche Politiker Günter Verheugen in seiner Zeit als Industriekommissar bei der Europäischen Union fest: »Man könnte überspitzt sagen, wir verbringen einen Großteil unserer Zeit damit, Probleme zu lösen, die es nicht gäbe, wenn es uns nicht gäbe.« Diesem Klagelied können sich auch viele Verantwortliche sozialer Organisationen und Unternehmen anschließen. Und doch ist das Murren über »die ausufernde Bürokratie« wohlfeil, wenn oft die gleichen Vertreter auf spezielle Regelungen für ihren Bereich oder in diesem und jenem »besonderen Fall« beharren. Das richtige Gleichgewicht zwischen Freiheit und Gerechtigkeit muss deshalb immer wieder neu justiert und gegebenenfalls ausgehalten werden. Peter Eichhorn macht dieses Spannungsverhältnis in seinem Einleitungsbeitrag in diesem Heft am Beispiel der Gesetzlichen Rentenversicherung deutlich: Das Bemühen, dem Einzelfall gerecht zu werden, stehen - von den Betroffenen vielfach als ungerecht empfundene - Pauschalregelungen gegenüber.

Die Hefte und Artikel der Zeitschrift SOZIALwirtschaft stehen für Abonnenten der Druckausgabe auch im Nomos-Zeitschriften-Portal (www.nomoszeitschriften.de) online zur Verfügung. Über die Zugangsmöglichkeiten für Privatbezieher und Institutionen informiert Sie gerne Aloisia Hohmann von der Vertriebsabteilung des Nomos-Verlages (hohmann@nomos.de).

Natürlich fehlt auch in dieser Ausgabe Ihrer Zeitschrift wieder das Thema, das Sie am meisten interessiert hätte. Da wir dieses nicht wissen: Tipps an die Redaktion sind hochwillkommen! 